\title{
PROCESSOS CRIATIVOS INDIVIDUAIS: EMA M E A FICÇÃO DO DESENHO CIENTÍFICO
}

INDIVIDUAL CREATIVE PROCESS: EMA M AND THE FICTION OFA

SCIENTIFIC DRAWING

Margarida Prieto

CIEBA/FBAUL

Resumo: Este artigo incide sobre a exposição de desenhos intitulada Animália \& Vegetália realizada pela artista portuguesa Ema M e onde é possível observar como uma exposição pode assumir um carácter site-specific apropriando-se do espaço expositivo e transformando-o quer pela montagem das obras, quer pela iluminação, quer pela performance que o observador é levado a fazer durante o processo de fruição dos desenhos expostos.

Palabras-chave: desenho, sequência, série, site-specific.

Abstract: This article is about an exhibition of drawings by the artist Ema M titled Animália \& Vegetália. In this exhibition is possible to observe how the site-specific concept can be applied using the scheme of montage, the illumination and the performance made by the observer/viewer/spectator of the work at the location.

Keywords: drawing, sequence, series, site-specific. 


\section{Introdução}

O trabalho gráfico de Ema M (Portugal, 1976) na exposição intitulada Animália \& Vegetália reflecte sobre os arquétipos da ilustração científica determinados durante o século XVIII: a descriptibilidade das imagens em relação aos seus modelos reais, os enquadramentos feitos pelo registo gráfico de molduras geométricas, desenhadas que mostram o que a legenda intitula, composições onde o centro predomina relativamente à periferia (bordo e limite da página de papel), a chave de uma codificação cromática que distingue os elementos constituintes do objecto observado, os meios gráficos - tinta-da-china e lápis-de-cor - cuja utilização e exploração expressiva remete, igualmente, para os exercícios de ilustração oitocentistas, e finalmente, os mesmos temas: a fauna (ou a animália), a flora (ou a vegetália) e os órgãos do corpo humano.

Ema M iniciou o seu percurso há 20 anos com um trabalho artístico variado em meios e linguagens: na tridimensionalidade apresenta objectos e livros de artista; na bidimensionalidade trabalha a pintura e o desenho. A exposição sobre a qual incide este artigo aborda o pensamento criativo patente numa série de 61desenhos que a artista intitulou Animália \& Vegetália e que foram realizados especificamente para serem mostrados na Sala de Exposições Temporárias do CAC - Centro de Artes e Cultura de Ponte de Sor, Alto Alentejo, Portugal.

\section{Desenvolvimento}

O conceito site-specific, tal como Miwon Knowo (2004) o defende é corretamente aplicado a situações artísticas precisas, únicas (happenings, instalações, performances, exposições, etc.), que excluem a possibilidade da(s) obra(s) em causa se deslocar(em) para outro lugar e/ou para outro contexto. Contudo, a espe- cificidade das montagens expositivas - no caso da pintura e do desenho, por exemplo - não excluem esse trânsito, por mais integradas que se mostrem (e sejam pre-determinadas na sua concepção) num contexto de exibição, ou seja, por mais site-specific que seja a sua concepção atendendo ao espaço expositivo que as vai receber. (Obviamente, a excepção a esta possibilidade de deslocação das obras site-specific dá-se com as pinturas murais e com os relevos escultóricos porque o próprio suporte é parte integrante do edifício onde se dão a ver.)

Há exemplos concretos de obras e de projectos artísticos pontuais que transitam entre espaços de exibição (por exemplo, em exposições itinerantes) sendo que, de cada vez, em cada um dos lugares onde se exibem, é convocada uma lógica de pertença ao lugar (que, entretanto, se altera ou é substituído). Mas o conceito operativo - site-specific - continua presente de um modo pertinente na medida em, de cada vez, há uma adaptação e um pensamento por parte do artista onde as relações entre a obra e o lugar se articulam e são tratadas como potência criativa. Ou seja, a montagem das obras nos lugares que as acolhem integra sempre o processo criativo: o exercício de fazer ver, ou de mostrar, ou de exibir uma obra implica que o artista está consciente do seu papel como agente intermediário quer na fruição estética, quer na percepção final dessa (sua) obra pelo observador ou espectador. De tal modo pode ser tratada esta relação (entre a obra e o lugar que a dá ver) de acordo com as especificidades arquitectónicas (morfologia, equipamentos) do espaço edificado que, em última instância, o artista leva a que o observador assuma as obras como se sempre ali estivessem, como sempre ali pertencessem - sendo este "ali" cada um dos espaços expositivos, mesmo quando se alteram (com acções de manutenção, por exemplo), ou 
Figura 01. Sala de Exposições Temporárias do CAC - Centro de Artes e Cultura. Vista da área útil de exposição. 2017. Ponte de Sor. Portugal. Cortesia da artista.

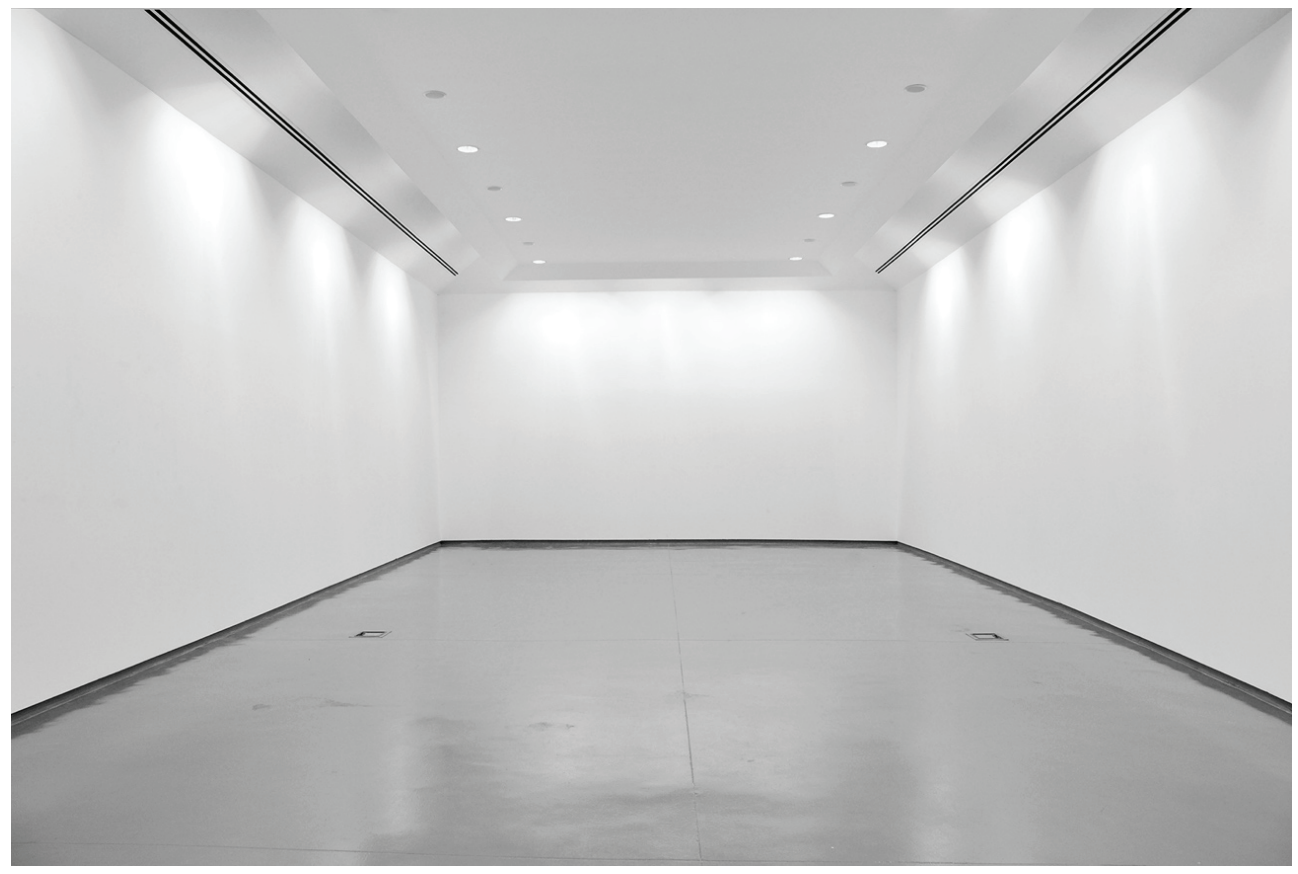

mesmo quando são substituídos por outros (ou seja, quando a obra transita entre lugares e espaços expositivos).

Em Animália \& Vegetália é possível verificar o efeito do conceito site-specific - ou seja, a sensação de pertença entre as obras e o espaço que as mostra -, e depois, a sua diluição, quer através de um livro de artista, quer através da individualidade e autonomia que cada desenho assume enquanto propriedade do coleccionador.

O que acontece com a obra gráfica de Ema M, enquanto exposição site-specific, é a aferição de um pensamento estruturado, consciente da importância da montagem dos desenhos naquela Sala de Exposições Temporárias do CAC - Centro de Artes e Cultura de Ponte de Sor (Figura 01).

A sala é um paralelepípedo rectangular com quatro metros de pé direito (altura). As duas paredes maiores têm cerca de quinze metros úteis (ou seja, que podem ser utilizados para expor) num total de vinte metros que incluem portas. Estas portas es- tão frente-a-frente, uma em cada parede e interrompem o contínuo circuito do olhar pelo perímetro branco do espaço; as duas paredes mais pequenas são assimétricas já que uma (a do fundo) é totalmente muro e mede cerca de oito metros, e a outra integra uma porta ao centro com janelas laterais. A decisão da artista é constituir um alinhamento ininterrupto de imagens que termina e acaba em cada uma das portas das paredes maiores, permitindo que o olhar percorra o espaço com as obras expostas ritmadamente, sem a distração que o mobiliário arquitectónico impõe (Figura 02, Figura 03, Figura 04). Na visita, entra-se e sai-se pela mesma porta - o que implica também um atravessamento da sala, depois de the percorrer o perímetro.

Assim, cada um dos desenhos é visto numa sucessão regular de espaçamentos (cerca de dez centímetros de distância) ocupando três das paredes deste paralele- 


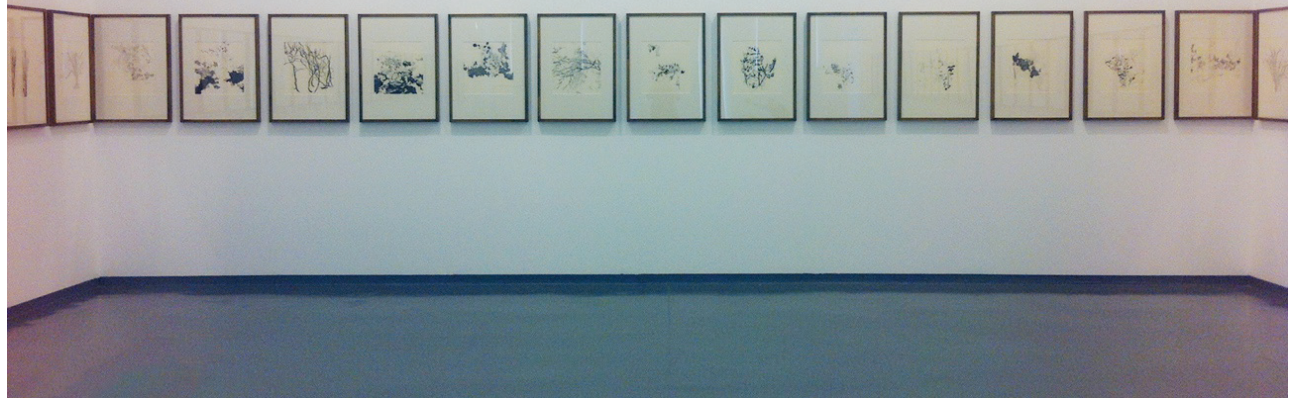

Figura 02. Sala de Exposições Temporárias do CAC - Centro de Artes e Cultura. Vista da área útil de exposição. 2017. Ponte de Sor. Portugal. Cortesia da artista.Título, autor, ano, fonte.

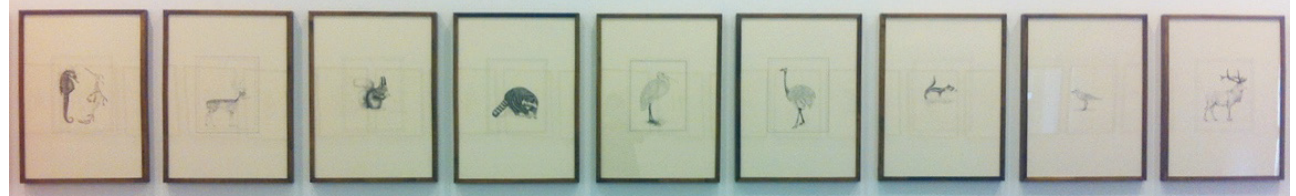

Figura 03. Sala de Exposições Temporárias do CAC - Centro de Artes e Cultura. Vista da área útil de exposição. 2017. Ponte de Sor. Portugal. Cortesia da artista. 
Figura 04. Sala de Exposições Temporárias do CAC - Centro de Artes e Cultura. Vista da área útil de exposição. 2017. Ponte de Sor. Portugal. Cortesia da artista.Título, autor, ano, fonte.
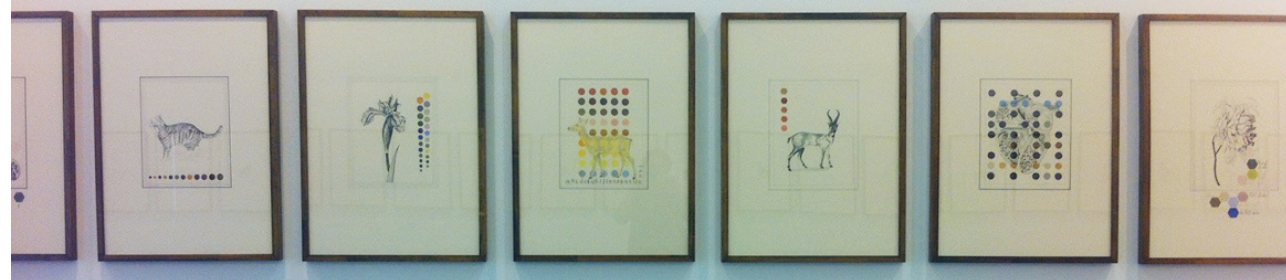

pípedo rectângular ${ }^{1}$. Os desenhos estão colocados ao nível do olhar - com o centro a metro e meio do chão - e agrupados por afinidades: um conjunto (24 desenhos) a tinta-da-china (exclusivamente) onde se veem representados animais (Figura 05), plantas (Figura 06) e órgãos do corpo humano (o coração e os pulmões) (Figura 07); um conjunto (13 desenhos) dedicado à flora do jardim botânico também exclusivamente a

1 A sala de Exposições Temporárias do Centro de Artes e Cultura de Ponte de Sor tenta aproximar-se da ideia do White cube americano. Contudo está poluída com portas, janelas, um tecto falso que oculta parcialmente os diferentes tipos de focos de luz, afastando-se desse espaço ideal e criando alguns constrangimentos nas decisões de montagem da exposição. Justamente, embora quem a visite exclusivamente entre e saia pela mesma porta, há uma segunda porta que comunica com outra sala, idêntica na configuração e mobiliário. Ou seja, esta sala transforma-se também num corredor. Não é por acaso que a Figura 01 mostra o lado oposto - o lado útil - deste espaço. Trata-se da área que é efetivamente usada pela artista em Animália \& Vegetália. tinta-da-china e com um registo experimental e exploratório do riscar; um conjunto (24 desenhos) ao qual acresce a cor aplicada com lápisde-cor (a colorir hexágonos e círculos) e letras desenhadas com uma caligrafia cuidada cuja função é legendar. Escreve Maria João Mayer Branco, a propósito da sua experiência de visita a esta exposição:

"Ora, antes de se tornar cara à arte moderna, e de implicar a ideia de espacialidade ou espacialização, a noção de série remete, e de um modo que se pode dizer essencial, para a noção de temporalidade (implícita, aliás, no termo "sequências"). Ela indica uma sucessão de partes ou elementos de um movimento com uma direcção unívoca, que não os subordina necessariamente a um destino pré-determinado. Assim também, mais do que seguir um caminho, seguir a sequência destes desenhos implica confiar numa indicação que nada ga- 
rante à partida, e que não possui, como se tornará evidente, nenhum ponto fixo de chegada, constituindo cada etapa ou cada desenho, em si e por si mesmo, a possibilidade de reconfigurar tanto a experiência do tempo, como a do espaço" (BRANCO, 2017, 55).

A série põe em relevo uma regulação, um encadeamento de idênticos, a duplicação representacional na repetição do modus operandi e, em exposição, a série implica igualmente uma visão e fruição das obras de modo sequencial, feita passo-a-passo, uma a seguir à outra. A acrescentar a esta sequencialidade, nestes desenhos pode pensar-se ainda sobre a estrutura do "tema e variações" que, justamente, apela à repetição como mecanismo de transformação. É claro que esta associação ao "tema e variações” é de ordem conceptual,ou seja, não se afere no formalismo da representação. E é verificável, por exemplo, nas estratégias de configuração da série, ou seja, no que faz com que cada desenho possa pertencer a um conjunto que, por sua vez configura a própria exposição tal como se instala neste espaço; ou possa conter vários conjuntos na medida que que seo divide por assuntos ou temáticas como é, por exemplo, a animália, que, por sua vez pode repartir em tipos: as aves ou os animais do céu, os mamíferos ou animais da terra, os peixes ou animais da água (usando aqui uma terminologia simplista na organização das espécies).

No espaço expositivo, é-se obrigado a caminhar ao mesmo tempo que se contempla cada desenho porque a distância (cerca de trinta e oito metros lineares de parede) é grande e a minúcia gráfica também. Para ver em detalhe é necessário ir, passo a passo, com os olhos postos sobre as obras de modo a vê-las de perto, uma de cada vez e, nestes movimentos - do corpo e do olhar - compreender que o conjunto (61 desenhos, no total) se constitui como série

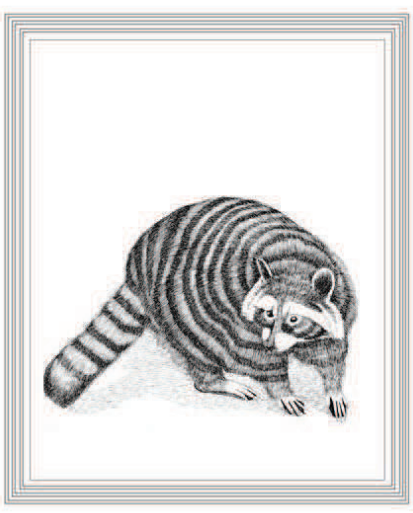

Figura 05. Animália \& Vegetália: guaxinim, Ema M, 2017, tinta-da-china sobre papel olin regular ivorie $250 \mathrm{~g} / \mathrm{m} 2,72 \times 51$ $\mathrm{cm}$, cortesia da artista.

e apresenta-se em sequência, para descobrir como todos os desenhos têm afinidades plásticas, conceptuais e formais, quer dizer, discernir o "tema" como mote - indicado no próprio título - e para apreender as diversidade de "variações" que o "tema" pode integrar.

As mais importantes afinidades formais desta série de desenhos são as seguintes:

1) uma moldura desenhada enquadrada na página de papel olin regular ivorie ligeiramente amarelado, com $250 \mathrm{~g} / \mathrm{m}^{2}$ e $72 \times 51$ centímetros.

2) No interior desta moldura está representada uma figura que pertence ao reino animal, ao reino vegetal ou ao corpo humano.

3) são utilizados os mesmos materiais riscadores: tinta-da-china (aplicada com canetas de arquiteto aristo nas espessuras $0.013 \mathrm{~mm}$, $0.018 \mathrm{~mm}$ e $0.025 \mathrm{~mm}$, ou seja, as três espessuras de risco mais finas) e lápis-de-cor;

4) obedecem às mesmas relações de composição consoante a tipologia. Se são representações de animais, plantas e órgãos, predomina a 
Figura 06. Animália \& Vegetália: couve-flor, Ema M, 2017, tinta-dachina sobre papel olin regular ivorie $250 \mathrm{~g} / \mathrm{m} 2$, $72 \times 51 \mathrm{~cm}$, cortesia da artista.

Figura 07. Animália \&Vegetália: coração humano, Ema M, 2017, tinta-da-china sobre papel olin regular ivorie $250 \mathrm{~g} / \mathrm{m} 2,72 \times 51 \mathrm{~cm}$, cortesia da artista.

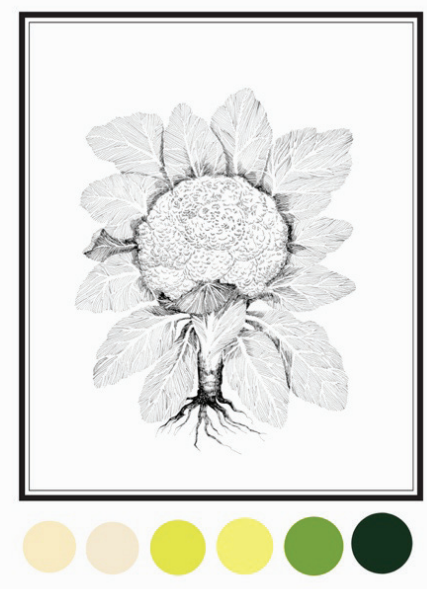

ocupação do centro da página papel e, com a inclusão de elementos geométricos coloridos (círculos e hexágonos) e/ou de texto manuscrito (que é percebido no contexto como legenda) o território gráfico expande-se e chega a sair do desenho da moldura enquadradora. Se são desenhos do Jardim Botânico, dá-se uma dispersão dos elementos gráficos pela folha de papel, criando composições de carácter abstratizante justamente pelo (ir)reconhecimento daquilo que está representado.

5) a marcada de um selo branco desenhado pela artista patente no fundo da página que funciona como assinatura e registo de autenticidade;

6) o emolduramento de todos os desenhos de modo similar, com um perfil simples e fino de madeira (pinho) escurecida, com vidro, e cujo resultado reenvia para o passado histórico das pranchas de ilustração.

Por outro lado, conseguem identificar-se as seguintes afinidades conceptuais:

i) a referência directa, por vezes sob a forma de citação, por vezes sob a forma de pastiche, à

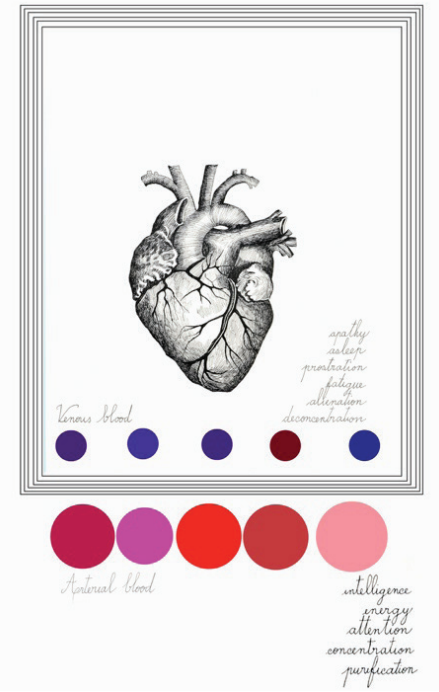

ilustração clássica do século XVII, com uma vocação pedagógica e enciclopédica;

ii) a homogeneidade da série (em vez da sucessão narrativa) e, como consequência, a alusão em potência à sua infinitude: é possível acrescentar sempre mais um desenho - o que coloca a dúvida de estarmos perante a série na sua totalidade.

iii) a expressividade do registo gráfico como modo de codificar texturas visuais, distinguindo-as, ou seja, a ênfase na descriptibilidade da representação face ao que representa;

iv) a intenção (a priori) de fazer uma montagem site-specific que, como consequência, condiciona o número de desenhos apresentados e é verificável no modo como efectivamente se concretiza a montagem. Mais uma vez, esta condição permite questionar a dimensão (quantidade) da série: o número final de desenhos em exposição é o total ou existem outros, que não estão expostos (?);

v) a inclusão de um desenho diferente dos 
restantes que, tal como num livro, principia o alinhamento e tem patente a inscrição do título da exposição e o nome da artista.

vi) a execução de um Livro de Artista com folhas soltas (ou monofolhas) em fac-simile (escala reduzida) que funciona como documento e testemunho do evento e, igualmente, um objecto autónomo e artístico.

Ao visitar esta exposição percebe-se que há um efeito de anamnese premeditado pela artista na concepção da exposição. Este efeito deve-se às seguintes estratégias:

a) o papel amarelado (que indica um tempo de existência, uma oxidação lenta das suas fibras);

b) as molduras em madeira escura com um perfil fino (que indicam uma maior preocupação com o conteúdo da representação do que com o aparato da obra; que remetem mais para a função de protecção e conservação do papel (que a moldura pressupõe) do que para a carga aurática e separadora que lhe é intrínseca enquanto parergon, ou seja, enquanto elemento de complemento à obra).

c) a opção de montagem em alinhamento, com intervalos regulares que distanciam as obras de dimensões idênticas. Neste ponto há que haver uma reflexão sobre as possibilidades de montagem pelas quais a artista não optou: em termos museológicos, as estratégias conceptuais de montagem pertinentes e aplicáveis a um conjunto (uma série) de obras podem ser sistematizadas assim: 1) por justaposição em grelha (caso as peças tenham dimensões idênticas); 2) ou como um puzzle, recorrendo à justaposição e ao encaixe (caso as peças tenham dimensões e proporções distintas); 3) em cabinet d'amateur para enfatizar a composição visual através do posicionamento (seja aleatório, seja preconcebido, seja diferente de cada vez e consoante a adaptação à área expositiva) e para salientar a diversidade das obras que compõem a exposição, quer na dimensão e proporção dos suportes, quer na variedade, mesmidade ou ausência de molduras, quer na possibilidade de agrupar temas, assuntos, projectos distintos. De todas estas possibilidades, Animália \& Vegetália mostra-se seguindo um alinhamento - o que acentua o carácter longitudinal do paralelepípedo rectangular que configura a sala de exposições. A estratégia vem impor um ritmo, uma cadência de visualização dada através de equidistâncias (dez centímetros apenas separam cada desenho), uma regularidade normatizada cuja altura é definida pelo olhar do observador. A montagem e posicionamento das obras deve obedecer à regra escolhida de um modo tal que o observador não se confunda, nem se disperse, garantido que a sequência de visualização tem prioridade no acto próprio da fruição de cada desenho. Não é por acaso que é esta a sucessão dos desenhos tal como os vemos em exposição: a sequência e sucessão permite perceber que há lógicas de agrupamentos temáticos nas três paredes que perfazem o perímetro da sala, nos seus trinta e oito metros de alinhamento. Compreende-se que há uma relação de adequação entre o número de desenhos expostos (61desenhos) e a dimensão do alinhamento (48 metros): na parede de oito metros estão exclusivamente desenhos que mostram o Jardim Botânico e nas duas paredes maiores há um grupo exclusivamente a preto e branco e outro com apontamentos de cor, respectivamente. A organização visual na mostração das obras depende da inteligência da artista, da sua capacidade de antecipação da composição concebida para a montagem dos desenhos compreendendo os constrangimentos arquitectónicos inerentes a este lugar (CAC) e neste sentido, há implicações site-specific. Implica considerar uma certa higienização do espaço expositivo, ou seja, manter a 
distância de todos os equipamentos legalmente obrigatórios como são os extintores, as placas de informação, os caixotes do lixo, as grelhas de ventilação, as calhas de iluminação, os elevadores, os bancos de descanso, etc., ou de pormenores arquitectónicos que se exibem como obstáculos ao olhar, numa visão perspectivada do espaço, como são, por exemplo, as estruturas de sustentação do tecto onde estão fixados os dispositivos de iluminação e, ainda, todas as portas e janelas que interrompem a brancura lisa da parede. E, porque toda esta parafernália é, também, de ordem visual, ou seja, participa do visível ao mesmo nível da obra pictórica, vai afectar profundamente o olhar do observador e a sua percepção da exposição. No acto próprio de fruição da exposição, o cérebro esforça-se para isolar o ruído visual daquilo que, efetivamente, é a experiência estética da obra - um esforço que em nada contribui para a contemplação.

A iluminação desta exposição é feita através de grandes focos que dispersam a luz pelo espaço. A sala assim iluminada não hierarquiza os desenhos nem cria auras de luz. Não elege, nem esconde. Os cantos da sala estão igualmente iluminados e, por isso, diluem-se na luz e permitem pensar o espaço como um circuito, sem desvios, sem barreiras, sem lugares obscurecidos. A sala é tornada uma nuvem branca de luz gigante. Mais uma vez, convocando Maria João Mayer Branco no que se refere à experiência do tempo através do caminhar, o facto da sala estar plenamente iluminada torna-a integralmente um caminho aberto, um território onde são as obras que indicam por onde seguir, no seu alinhamento ordeiro, e obrigam, nesse movimento, a que o observador seja performativo e faça o movimento do caminhante, quase colado à parede, levando o tempo necessário sem pressa - para ver cada desenho, para parar (se necessário) e retomar o passo. Entre pausa e movimento, entre paragem e deslocação, é possivel, a qualquer momento, sair do caminho, atravessar a sala, voltar a um desenho já visto, revisitar outro que ficou na memória como preferido, vacilar, comparar, derivar.

Em Animália \& Vegetália, referência branca e limpa do espaço conceptual de exposição identificado como White cube vem, paradoxalmente, potenciar o contraste entre o que é novo e o que é antigo, fazendo salientar a referência que estes desenhos fazem - ou melhor, ficcionam - aos arquétipos da ilustração oitocentista. O branco quer da luz, quer do tecto, quer das paredes contrasta com o amarelo suave dos papéis desenhados, com a inscrição manuscrita, gestual da mão, com as molduras castanhas, de madeira. Se esta série é informada nos códigos de representação gráfica da ilustração científica é porque os desenhos nos remetem para as imagens que se encontram em livros fac-símile e que também mostram os animais, as plantas, as pessoas e as paisagens de lugares distantes encontrados durante viagens de descoberta. No século XVII, as equipas técnicas em viagem integravam artistas cuja função era registar as peculiaridades dos territórios (relativamente ao que era familiar). A ilustração científica enriqueceu o imaginário sobre o mundo, documentando-a. Estabeleceu uma função pedagógica para estas imagens do mundo e, com elas, ensinou a vê-lo (e a compreender a sua diversidade).

Há três tipos de desenhos neste conjunto, embora o emolduramento final os homogeneíze num rectângulo vertical com $72 \times 51 \mathrm{~cm}$. O papel é sempre o mesmo (olin regular ivorie 250g/m2 250g/m2), cortado à medida. E porque é sem texturas torna-se ideal para fazer correr a ponta das canetas de tinta-da-china. Nos desenhos que ocupam dimensão total da página de papel está delimitado um enquadramento onde todas as molduras desenhadas vão va- 


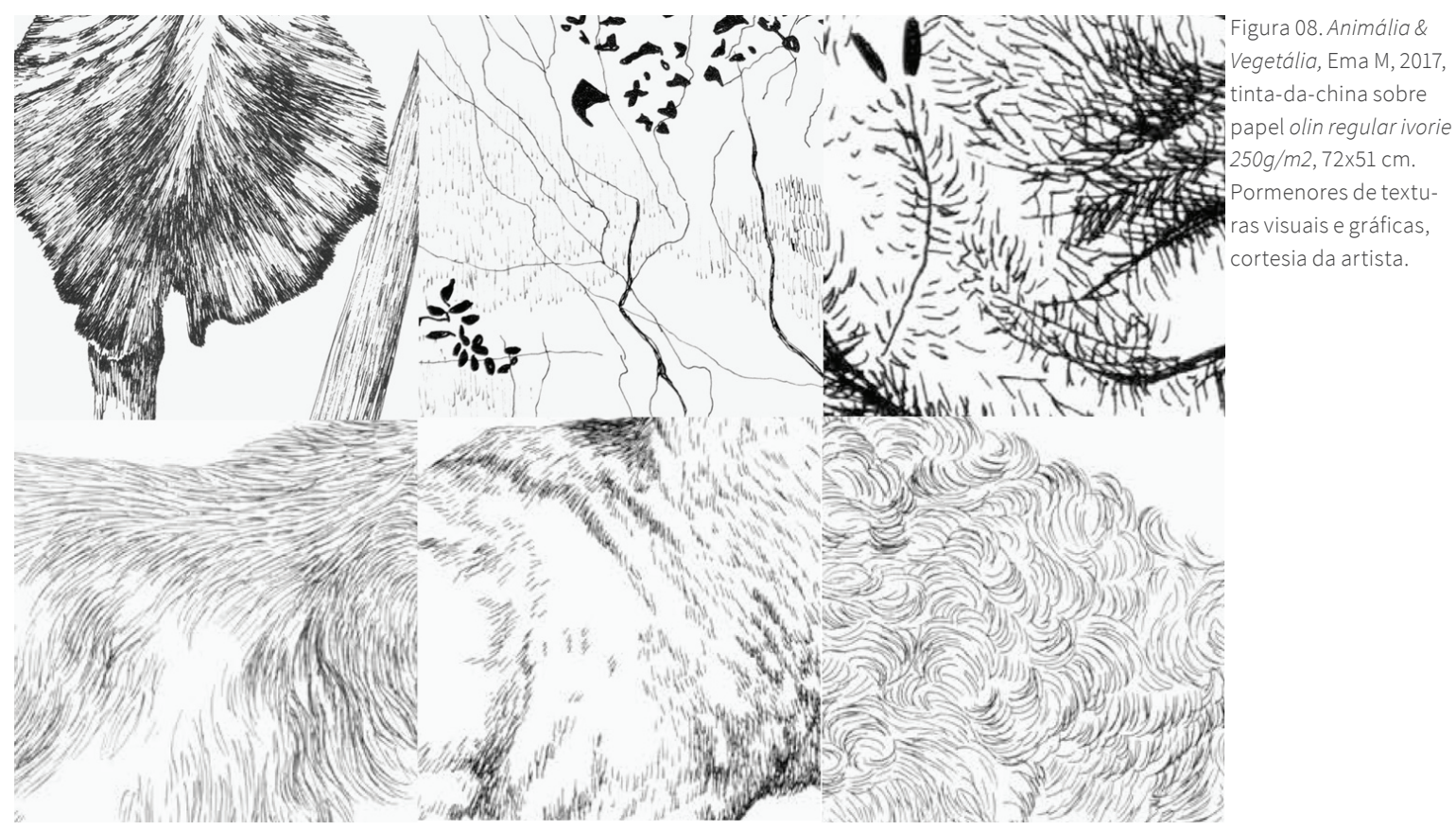

riando entre si. A representação dos animais, das plantas e dos órgãos humanos mostra um virtuosismo expressivo do traço na criação de texturas de superfície (folhas, raízes, pêlos curtos e compridos, escamas, penas, etc.) (Figura 08). Esta diversidade do traço, assume a natureza gráfica do desenhar como marca, rasto do gesto e do pensamento e, simultaneamente, é imprescindível na descriptibilidade necessária à representação e à consequente distinção formal dos "seres" que ilustra. Conceptualmente, permite compreender o princípio que separa os signos visuais em duas famílias: os icónicos ou figurativos (que têm uma relação de semeIhança com o real exterior, representações da ordem da mimése); e os picturais ou plásticos que se determinam na técnica e nas suas marcas (a mancha, a pincelada, o corpo de tinta, a textura da superfície suporte). Os primeiros tomam em consideração a percepção normal do olhar; os segundos exigem uma aproximação, um movimento de zoom em direcção à página

desenhada que, se por um lado impede o reconhecimento dos signos icónicos, por outro dá a ver (em pormenor) os signos plásticos. De modo inverso, também o movimento de afastamento vai enevoar os signos figurativos até à sua indistinção, onde então passam ser vistos como a manchas difusas e a pertencer ao grupo dos

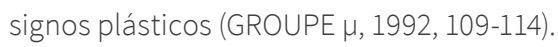

Porém, ao contrário do que seria de esperar num trabalho desta natureza, a seriedade das imagens é substituída por um certo humor que se deve, sobretudo, ao facto de, efectivamente, não se tratar de uma prancha de ilustração do século XVII mas de um desenho contemporâneo que, embora se aproprie de regras e códigos da ilustração científica, é independente da dimensão pedagógica e enciclopédia inerente a este disciplina. Também porque, nestes desenhos é, por vezes, acrescentado um conjunto de formas geométricas preenchidas com lápis-de-cor, num exercício de colagem conceptual. A expressão gráfica destes materiais riscadores convoca 
Figura 09. Animália \& Vegetália: cabra, Ema M, 2017, tinta-da-china sobre papel olin regular ivorie $250 \mathrm{~g} / \mathrm{m} 2$, $72 \times 51 \mathrm{~cm}$, cortesia da artista.

Figura 10. Animália \& Vegetália: rosa, Ema M, 2017, tinta-da-china sobre papel olin regularivorie $250 \mathrm{~g} / \mathrm{m} 2$ $72 \times 51 \mathrm{~cm}$, cortesia da artista.

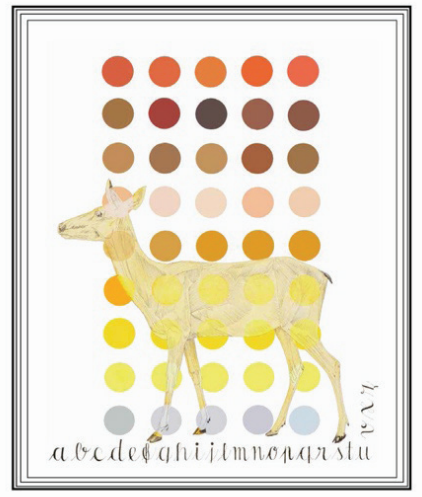

os registos infantis. Há ainda a inserção de certas palavras escritas a tinta-da-china: nomes de cores, nomes de sentimentos, letras avulsas, números, sequências de letras e números. A aplicação da cor a lápis acrescenta uma dimensão lúdica que torna o desenho alegre, leve, como se menos sério, menos científico, menos grave. A cor acentua o humor, ainda que esteja delimitada por figuras geométricas e toda a geometria parece conter uma dimensão de ordem e de racionalidade, embora exista uma geometria patente na natureza e nas formas naturais que só é compreendida e aplicável às coisas feitas pelo homem através do uso da observação, da matemática, como tão bem esclarece Matila Ghyka. Todos estes elementos associados remetem, cada vez mais, para aquilo que é a informação de uma prancha de ilustração científica. Mas não deixa de ser um desenho híbrido, repleto de colagens conceptuais que são garantidas quer pelas palavras inscritas (que nada têm que ver com o que está representado e por isso, esca-

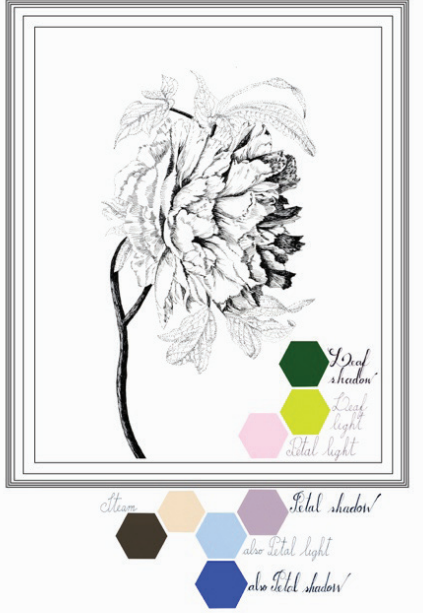

pam à função de legenda patente nas lógicas da ilustração), quer pelos elementos geométricos coloridos. Assim, há um grupo de desenhos (só) a tinta-da-china, e outro, de composição mais elaborada que articula palavras, cor e formas geométricas. Em exposição, contraste entre estes dois grupos parece potenciador das suas diferenças.

O terceiro grupo é composto pelo conjunto de desenhos que representam pequenos pormenores do Jardim Botânico de Coimbra e é realizado a tinta-da-china exclusivamente. Nestes desenhos assume-se um quadrado como enquadramento. 0 que falta para completar o rectângulo homogeneizador é preenchido com um passe-partout. Trata-se de uma pesquisa plástica e gráfica do desenho e, por isso, cada uma destas obras oscila entre o abstrato e o figurativo. A dimensão exploratória do desenhar como prática criativa é o que parece estar aqui a ser exibido. Em exposição, estes desenhos são mostrados na parede do fundo, a mais estreita (Figura 01).

Ao visitar esta exposição, tem-se de imediato 


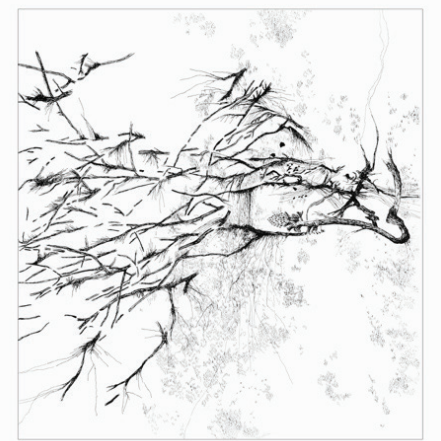

a sensação de que há muito trabalho realizado. A impressão que os desenhos deixam, ainda sem os vermos em detalhe, é a de uma fila serrada, contínua, uma risca que afecta e se desenha pela parede branca do espaço expositivo. A parede é como uma página onde a brancura é destruída com uma risca horizontal que a separa em duas parte, a de baixo que se conjuga com o chão, e a de cima que se articula com tecto. Depois, a curiosidade leva a aproximar-nos de cada desenho, um por um, e espantar-nos pela minucia do registo, pelo inusitado do tema, que nos remete para uma época sem pressas, uma época de dedicação a um (a)fazer que se demora, que exige atenção e tempo. Dá-se um efeito de surpresa e de encantamento. Uma certa nostalgia, também. E o conceito site-specific afectanos pela ordem que impera na sala. Uma ordem clara e limpa e para a qual contribui a claridade da luz artificial que transforma o espaço numa nuvem branca, funciona como uma âncora que oscile entre o presente e o passado, entre este e

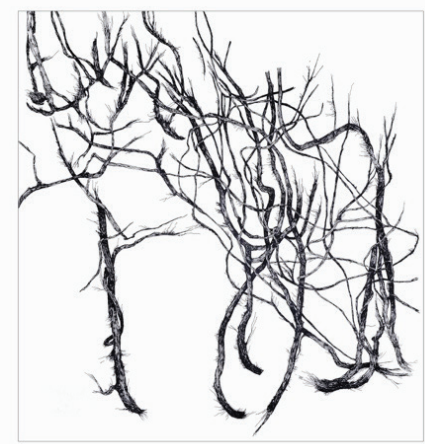

Figura 11. Animália \& Vegetália: Jardim Botânico, Ema M, 2017, tinta-da-china sobre papel olin regularivorie $250 \mathrm{~g} / \mathrm{m} 2$, $72 \times 51 \mathrm{~cm}$, cortesia da artista.

Figura 12. Animália \& Vegetália: Jardim Botânico, Ema M, 2017, tinta-da-china sobre papel olin regularivorie $250 \mathrm{~g} / \mathrm{m} 2$, $72 \times 51 \mathrm{~cm}$, cortesia da artista. outros tempos. O espaço reconfigura um lugar onírico, encantatório, aberto (à memória, ao caminhar), destemido.

Mas a exposição não termina naquele espaço. Ela transforma-se num livro - um Livro de Artista - concebido desde o princípio para substituir a experiência in loco e servir como dádiva. Este livro quer oferecer o impossível: levar todos os desenhos para casa e, ainda, a experiência da exposição. Por isso, o livro é desenhado numa versão fac-simile que mantem o mesmo papel usado nos desenhos. A monofolhas estão numeradas pela necessidade de estabelecer uma ordem entre os desenhos e, igualmente, nos textos (o da artista e o da ensaísta). Na frente da foIha está o desenho inteiro, no verso um detalhe. O trabalho de design é integralmente de Ema M. A analogia entre a Sala de Exposições e este Livro-de-Artista como objecto abre a uma maior compreensão do projecto gráfico de Animália \& Vegetália. Os desenhos em exposição são, comparativamente com os do livro, maiores na 
Artista: Animália \&

Vegetália, Ema M, 2017,

impressão digital so-

bre papel olin regular

ivorie $250 \mathrm{~g} / \mathrm{m} 2$, 134 pá-

ginas. Edição Câmara

Municipal de Ponte

Sor e Fundações das

Casas de Fronteira e

Alorna. Cortesia da

artista.

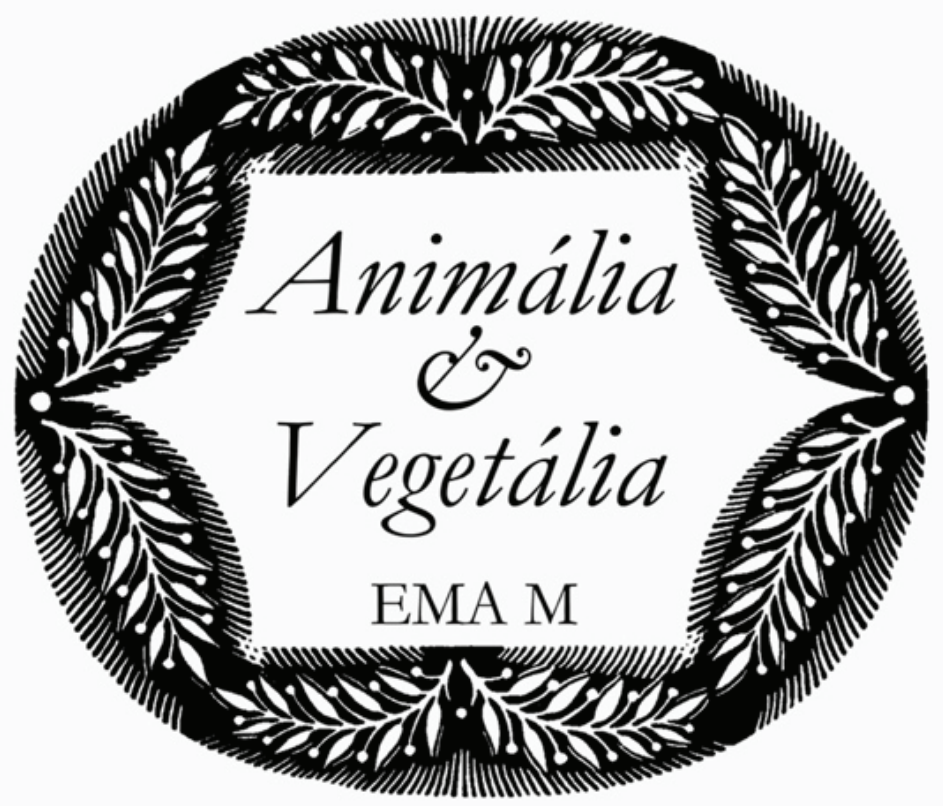

dimensão porque são para estar pendurados na parede, para serem vistos com os olhos e com o corpo a caminhar lentamente pelo espaço. Os que vemos no Livro têm uma dimensão menor para os podermos folhear e, neste gesto - mais íntimo e contido -, há uma contenção do movimento do corpo. Cada desenho exposto pode sair da série e emancipar-se com autonomia. O mesmo acontece com as monofolhas cuja eleição remete para as pranchas individuais de ilustração científica que se utilizam para decorar as habitações, à maneira dos costumes barrocos no norte da Europa. Neste sentido, a concepção deste Livro de Artista continua 
uma certa lógica prevista para montagem da exposição, alterando apenas o loco (o edifício para o livro).

\section{Conclusão}

Muito no espírito do nosso tempo, os artistas compreendem que a montagem das suas exposições começa no minuto em que iniciam a concepção da sua obra. Conceber o vão fazer e o que vão mostrar, determinar a quantidade de peças exibidas (a sua inter-relação e co- dependência), considerar a relação que estabelecem com o espaço que as exibe, entre outras condicionantes, é fundamental para a eficácia da recepção, é imprescindivel para criar e exceder as expectativas do observador e visitante. Neste sentido, o conceito site-specific é determinante para o sucesso do projecto. No caso da exposição Animália \& Vegetália esta harmonia das obras com o lugar é absolutamente visível através de um alinhamento que as sequencia e, nesse movimento, organiza o espaço expositivo. Se há uma impressão de "viagem ao passado" é porque os desenhos são uma actualização do exercício de desenhar a partir do real, do exercício de codificar graficamente as superfícies das coisas da natureza. É clara a referência à ilustração científica do século XVIII, mas nestes desenhos acrescenta-se uma dimensão lúdica que não existia - nem existe - naquela área disciplinar. São menos ilustrativos e mais criativos, na medida em que neles se conjugam elementos que se desviam de uma dimensão enciclopédica, catalogadora, mas acrescentam humor e leveza às imagens. A exposição desdobra-se, por fim, num Livro de Artista que colmata o desejo de ter dos desenhos à mão, e voltar a olhá-los, de vez em quando.

\section{Referências:}

BRANCO, Maria João Mayer (2016), "A gaia Ciência”, in Animália \& Vegetália, Ponte de Sor, ed. Centro de Artes e Cultura / Fundação das Casas de Fronteira e Alorna.

KWON, Miwon (2004), One Place After Another: Site-Specific Art and Locational Identity, The MIT Press, ISBN-13: 978-0262612029

GHYKA, Matila (1931), Le Nombre d'or, Paris, Librairie Gallimard

GHYKA, Matila (1946), The Geometry of Art and Life, Dover Books

GROUPE $\mu$ (1992), Traité du signe visual: pour une rhétorique de l'image, Paris, Editions du Seuil, col. La couleur des idées, (1ª ed.). 